East African Medical Journal Vol. 87 No 6 June 2010

SILENT CIRCULATION OF ARBOVIRUSES IN CAMEROON

E. B. Fokam, BSc, Maîtrise, MPhil, PhD, Lecturer, Department of Plant and Animal Sciences, and Biotechnology Unit, University of Buea, Cameroon, L. D. Levai, BSc, MSc, Research Fellow, Institut de Recherche Agronomique pour le Développement, Ekona, Cameroon, H. Guzman, BSc, Researcher, Department of Pathology and Center for Biodefense and Emerging Infectious Diseases, University of Texas Medical Branch, Galveston, Texas, P.A. Amelia, BSc, Researcher, Department of Pathology and Center for Biodefense and Emerging Infectious Diseases, University of Texas Medical Branch, Galveston, Texas, V.P. K. Titanji, PhD, Professor, Department of Biochemistry and Microbiology, and Biotechnology Unit, University of Buea, Cameroon, R. B. Tesh, MD, Professor, Department of Pathology and Center for Biodefense and Emerging Infectious Diseases, University of Texas Medical Branch, Galveston, Texas and S. C. Weaver, PhD, Professor, Institute for Human Infections and Immunity and Department of Pathology, University of Texas Medical Branch, Galveston, Texas

Request for reprints to: Dr. E. B. Fokam, Department of Plant and Animal Sciences, University of Buea, P.O. Box 63 Buea, Cameroon

\title{
SILENT CIRCULATION OF ARBOVIRUSES IN CAMEROON
}

\author{
E. B. FOKAM, L. D. LEVAI, H. GUZMAN, P.A. AMELIA, V. P. K. TITANJI, R. B. TESH \\ and S. C. WEAVER
}

\begin{abstract}
Objectives: To investigate the silent circulation and transmission of arthropod-borne viruses (arboviruses) in the Fako Division of Cameroon.

Design: This survey was conducted based on clinical observations and laboratory diagnosis; field collections of mosquitoes.

Setting: This study was conducted in the Fako Division of South West Cameroon.

Subjects: One hundred and two sera were obtained from febrile patients (with negative laboratory findings for malaria and typhoid fever) at clinics in the Fako Division, and diurnal anthropophilic mosquitoes $(4,764)$ collected.

Interventions: Virus isolation was attempted from these, and sera were screened for antibodies against 18 African arboviruses by haemagglutination inhibition (HI) and complement fixation (CF) tests.

Results: No virus was isolated. Fifty three of $79(67.1 \%)$ sera reacted with one or more viral antigens. Twenty nine sera $(36.7 \%)$ reacted with members of the genus Alphavirus, with Chikungunya $(\mathrm{CHIKV})$ and $\mathrm{O}^{\prime}$ nyong-nyong $(\mathrm{ONNV})$ viruses as the most frequent $(34.2 \%)$. Forty six sera $(58.2 \%)$ reacted with members of the genus Flavivirus: $24(30.4 \%)$ were cross-reactive, but $11.4 \%$ reacted monotypically with Zika, $5.1 \%$ with yellow fever virus (YFV), 5.1\% with dengue virus-2 (DENV-2), 2.5\% with DENV-1 and 1.3\% with Wesselsbron virus, respectively. The plaque reduction neutralisation test used to specify the agent that elicited the response could not resolve $33.3 \%$ of the cross reactions between CHIKV and ONNV. Neutralising antibody titres against ONNV and CHIKV were very high indicating probable re-infection.

Conclusion: Our results indicate previously undetected circulation of arboviruses in Cameroon, and suggest that they are important, overlooked public health problems.
\end{abstract}

\section{INTRODUCTION}

Arthropod-borneviruses (arboviruses) are responsible for numerous humaninfections worldwide, and cause both epidemics of serious disease as well as endemic disease in some areas. Despite documented evidence for their presence in virtually all African countries including Cameroon (1), they are almost never part of routine laboratory diagnoses and very often go unnoticed, probably accounting for morbidity and frequent debilitation. Arboviral infections indiscriminately manifest in humans with symptoms similar to those of malaria and typhoid fever, the most common causes of febrileillnessinsub-Saharan Africa. The most common arboviral diseases of humans include dengue fever (DEN), yellow fever (YF) and chikungunya (CHIK). Dengue is characterised by fever, severe myalgia and arthralgia, and rash. Except for the painful symptoms, which led to the name "breakbrone fever," classic DEN is a relatively mild disease and is usually not fatal (2). A more serious form of DEN, dengue haemorrhagic fever (DHF), is characterised by bleeding from the skin, gums, and gastrointestinal tract and sometimes by circulatory 
failure and shock $(3,4)$. DEN is the fastest growing disease of the world with more than 2 billion people at risk, and the World Health Organization (WHO) estimates that "there may be 50 million cases of dengue infection worldwide every year" (4). Chikungunya is a dengue-like disease that can occur as a massive epidemic, as was the case in early 2006 on the French island of La Réunion (5). Yellow fever is caused by the yellow fever virus (YFV) and begins with fever, chills, headache, and backache, followed by nausea and vomiting, followed by a yellowing of the skin termed jaundice that gives the disease its name. In severe cases, the virus produceslesions in the infected organs, and haemorrhage occurs.

These three arboviruses and many others are transmitted by diurnally active mosquitoes, mainly from thegenus Aedes, even though some other groups may be important vectors. Numerous mosquitoes have been suspected and some incriminated as vectors of various arboviruses in Cameroon during the colonial and early postcolonial eras by surveys conducted by scientists from the Centre Pasteur and Office dela RechercheScientifiqueet TechniqueOutreMer (ORSTOM). Unfortunately, after the last (1976) publication of these surveys, there was a 25-year gap before Fontenille and Toto reported theintroduction of the Aedes albopictus, a potential new vector of DF and YF into southern Cameroon (6-8). Later, Ndip et al. (9) Kuniholm et al. (10) and Demanou et al. (11), reported prevalence of antibodies (Abs) to some arboviruses in the serum of febrile patients in Cameroon, and Peyrefitte et al., isolated the CHIKV from a patient. In this survey, we sought to further investigate the latent circulation of arboviruses, characterise the agents and assess the risk of infection in Cameroon, with reference to the Fako Division (Figure 1).

Figure 1

Map of the Fako division showing the locations of collection

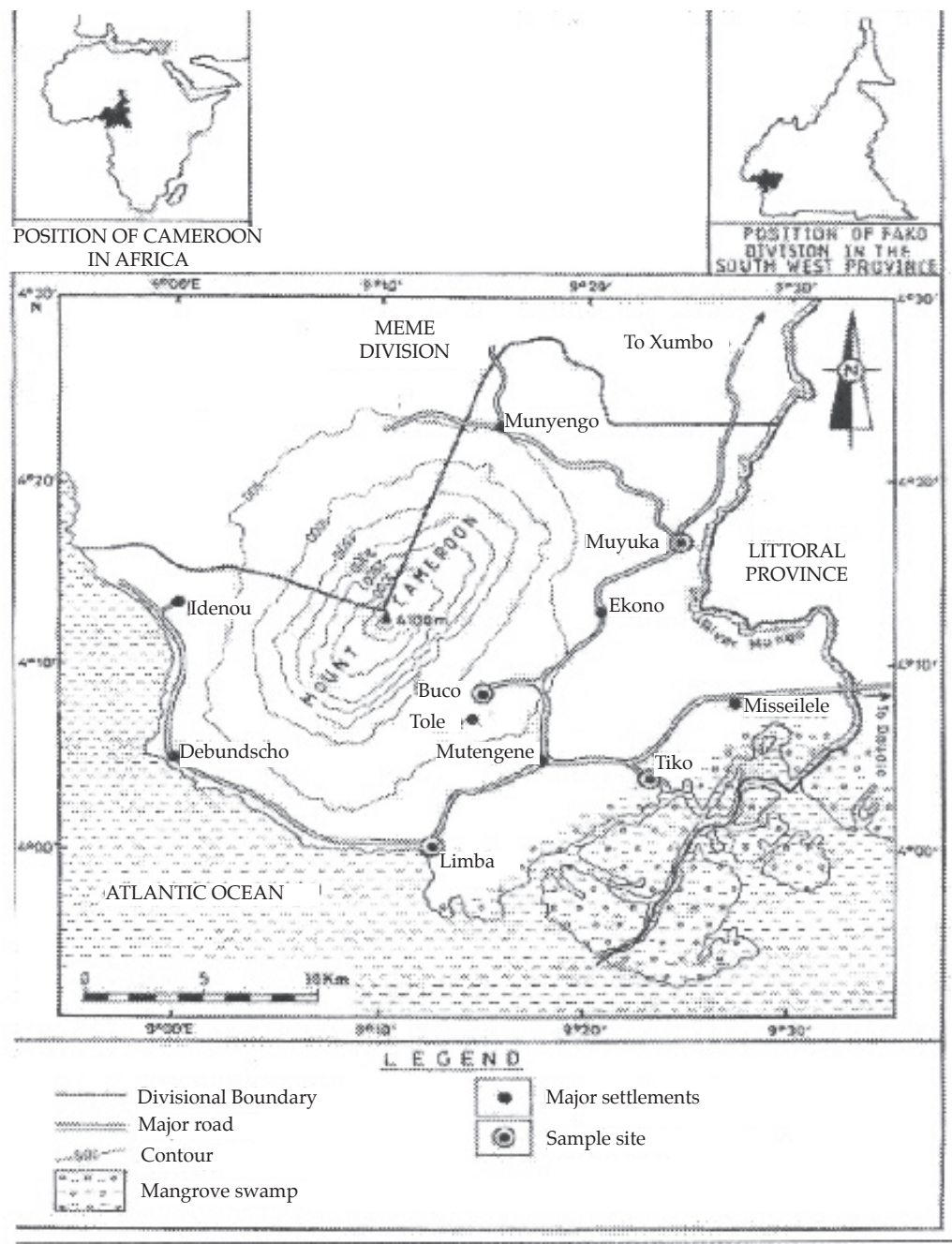




\section{MATERIALS AND METHODS}

Study population: One hundred and two sera were anonymously collected from consenting febrile patients (59 males and 43 females) consulting at the Provincial Hospital Annex and Mount Mary Health Centre in Buea, and the Cameroon Development Corporation Central Clinic, Tiko. These are the major settlements in the Fako division and comprise almost $80 \%$ of the population. The hospitals in Buea and Tiko receive a very large number of patients from the region, with patients admitted from throughout the division. Laboratory diagnoses had excluded malaria and typhoid fever, the most common causes of fevers in Cameroon. Blood was collected in clean collection tubes, the serum separated and stored at $-80^{\circ} \mathrm{C}$.

Diurnally active anthropophilic mosquitoes $(4,764)$ were obtained from human landing catches in Buea, Limbe and Tiko, by experienced collectors who were vaccinated against $\mathrm{YF}$, received malaria medication, and had taken ivermectin to prevent onchocerciasis/river blindness. All collections (serum and mosquitoes) strictly followed our protocol approved by the Ministry of Public Health and the administrations of the participating hospitals / clinics. Mosquitoes were equally stored at $-80^{\circ} \mathrm{C}$. All samples were transported on dry ice to the University of Texas Medical Branch (UTMB), Galveston, Texas, USA.

Virus isolation attempts: Although there was a conspicuous breach in the chain of cold during the transportation of the samples to the USA, virus isolation was nevertheless attempted (3). Mosquitoes were sorted on a chill table and pooled by species and by sex, homogenised in cell culture medium, centrifuged, filtered and $300 \mu$ Lof each poolinoculated in a monolayer of mosquito $(\mathrm{C} 6 / 36)$ and African green monkey kidney (Vero) cells. Human sera were inoculated directly into monolayers of Vero cells $(300 \mu \mathrm{L})$ or diluted $(1: 10)$ and inoculated into C6/36 cells. Cell cultures were incubated at appropriate temperature for 7 and 14 days respectively for $\mathrm{C}^{6 / 36}$ and Vero, and monitored daily for cytopathic effect (CPE). At theend of theincubation period, cellswereharvested and screened by indirect immunofluorescence assay using mouse Abs against three members of the genus Flavivirus (YFV, DENV and ZIKAV). All virus isolation attempts were negative, possibly because of therupture in the chain of cold, and are not further discussed in this paper. However, these failures and increasing difficultiesininternational transportation of diagnostic material stressed the need for the transfer of equipment (for appropriate containment) and diagnostic reagents to Cameroon. This is being properly addressed, and the development of high level biosafety containment facilities is underway.

Preparation of antigens: Arbovirus antigens (Ags) were obtained from the World Reference Collection for Emerging VirusesandArboviruses(WRCEVA) atUTMB (Table1).Prior touseinhaemagglutination inhibition test
(HI),Agsweretitrated todetermineoptimalconcentration (4 $\mathrm{U}$ used in test) and $\mathrm{pH}$ to use.

Haemagglutination-inhibition tests: The sera were screened for the presence of Abs to African arboviruses. They were treated with acetone to remove lipids and non-specific inhibitors, and absorbed with goose cells to remove natural agglutinins. Titres were recorded as the highest dilution causing total or almost total inhibition of agglutination.

Complement fixation: Complement fixation test (CF) was performed using 2 units of complement and some of the Ags previously prepared. The sera were incubated at $60^{\circ} \mathrm{C}$ for 20 minutes to inactivate naturally occurring human complement beforetesting(13). Titres were recorded as the highest dilution giving $3+$ or $4+$ fixation of complement on a scale of 0 to $4+$.

Plaque reduction neutralisation tests: Because some sera cross-reacted with multipleAgs (especially CHIK and ONNV), they were tested by the plaque reduction neutralisation test (PRNT) to discriminate between these infections. The Ross strain of the CHIKV and the MP730 strain of the ONNV obtained from the WRCEVA were amplified and titrated. Each virus stock was diluted to a titre of $800 \mathrm{PFU} / \mathrm{ml}$ (plaque forming units per $\mathrm{ml}$ ) and used in all assays. Serial 2fold dilutions of the 27 sera cross-reactive with CHIKV and ONNV were prepared, mixed withequal volumes of the virus stock, incubated at $4^{\circ} \mathrm{C}$ overnight and inoculated into monolayers of Vero cells. The cultures were then incubated until plaques formed. The titre of the neutralising Abs was considered as the highest dilution that would neutralise $80 \%$ or more of the virus in the stock used. Cross-reaction was resolved if there was a 4-fold or greater difference in the titre of the Abs to one of the viruses over the other.

\section{RESULTS}

Haemagglutination-inhibition: A total of 79 human sera was tested by $\mathrm{HI}$ for antibodies against 18 arthropodborne viruses. The results (Table 1) indicate that 53(67.1 $\%$ ) sera reacted with one or more antigens. No evidence was found ofimmunity toviruses of the Orthobunyavirus, Phlebovirus or Thogotovirus genera. Twenty nine sera (36.7\%) reacted with Alphavirus antigens, with CHIKV and ONNV as the most frequent (34.2\%). Forty six sera $(58.2 \%)$ reacted with Flavivirus antigens. Of this total, $24(30.4 \%)$ were cross-reactions, but four $(5.1 \%)$ reacted monotypically with YF, nine $(11.4 \%)$ with ZIKA, one (1.3\%) with Wesselsbron (WSL) and two (2.5\%) with a titre against YF and ZIKA, respectively, greater than with other Flavivirus antigens. In addition, four (5.1\%) sera reacted with DEN-2 and two (2.5\%) with DEN-1.

Complement fixation: Eighteen serawerestudied using CF test and the presence of antibodies was confirmed in six sera reacting with $\mathrm{CHIK}$ and $\mathrm{ONN}$ antigens, six sera reacting with ZIKA among $10 \mathrm{HI}$ positive, and one with $\mathrm{SF}$ (Table 2). These results indicate that most responses to ONNV were recent responses (titre $\geq 1: 32$ ). 


\section{Table 1}

List of antigens used and prevalence of haemagglutination inhibition antibodies in sera from Cameroonian patients

\begin{tabular}{|c|c|c|c|}
\hline Genus & Antigen & Number positive $(\%)$ & Geometric mean titre \\
\hline \multirow[t]{5}{*}{ Alphavirus } & Chikungunya (CHIKV) & $27(34.2)$ & 173 \\
\hline & Middleburg (MIDV) & $21(26.6)$ & 35 \\
\hline & O'nyong nyong (ONNV) & $27(34.2)$ & 179 \\
\hline & Semliki Forest (SFV) & $21(26.6)$ & 41 \\
\hline & Sindbis (SINDV) & $11(13.9)$ & 40 \\
\hline \multirow[t]{9}{*}{ Flavivirus } & Dengue-1 (DENV-1) & $30(38.0)$ & 76 \\
\hline & Dengue-2 (DENV-2) & $31(39.2)$ & 100 \\
\hline & Dengue-3 (DENV-3) & $28(35.4)$ & 49 \\
\hline & Dengue-4 (DENV-4) & $28(35.4)$ & 66 \\
\hline & Spondweni (SPOV) & $19(24.1)$ & 58 \\
\hline & Wesselbron (WSLV) & $33(41.8)$ & 74 \\
\hline & West Nile (WNV) & $27(34.17)$ & 49 \\
\hline & Yellow fever (YFV) & $34(43.03)$ & 65 \\
\hline & Zika (ZIKAV) & $30(37.97)$ & 101 \\
\hline \multirow[t]{2}{*}{ Orthobunyavirus } & Ingwavuma (INGV) & 0 & 0 \\
\hline & Tahyna (TAHV) & 0 & 0 \\
\hline Phlebovirus & Rift Valley (RVFV) & 0 & 0 \\
\hline Thogotovirus & Thogotovirus (THOV) & 0 & 0 \\
\hline
\end{tabular}

Table 2

Complement fixation test results

\begin{tabular}{|c|c|c|c|c|c|c|c|}
\hline \multirow{2}{*}{ Sample ID } & \multicolumn{2}{|c|}{ Alphavirus } & \multicolumn{5}{|c|}{ Flavivirus } \\
\hline & ONN & CHIK & SF & MID & YF & WSL & ZIKA \\
\hline 2 & & & & & $16 / \geq 32$ & $16 / \geq 32$ & \\
\hline 18 & & & & & & & $8 / 8(1: 80)$ \\
\hline 22 & & & & & & & $0(1: 40)$ \\
\hline 46 & & & & & & & $0(1: 80)$ \\
\hline 47 & & & & & & & $16 / 8(1: 160)$ \\
\hline 50 & & & & & & & $32 / 8(1: 320)$ \\
\hline 51 & & & & & & & $32 / 8(1: 320)$ \\
\hline 59 & & & & & & & $0(1: 40)$ \\
\hline 65 & & & & & & & $0(1: 80)$ \\
\hline 77 & & & & & & & $16 / 8(1: 80)$ \\
\hline 78 & & & & & & & $16 / 8(1: 160)$ \\
\hline 5 & $32 / \geq 32$ & $32 / 8$ & & & & & \\
\hline 15 & $32 / \geq 32$ & 0 & & & & & \\
\hline 37 & $64 / \geq 32$ & $8 / 8$ & & & & & \\
\hline 45 & $32 / \geq 32$ & 0 & & & & & \\
\hline 52 & & & $16 / \geq 32$ & 0 & & & \\
\hline 58 & $\geq 256 / \geq 32$ & 0 & & & & & \\
\hline 69 & $64 / \geq 32$ & 0 & & & & & \\
\hline
\end{tabular}


Numerator=titre of Ag used; denominator=titre of $\mathrm{Ab}$ used. Ab titre of 1:32 or more represents primary response; brackets indicate $\mathrm{HI}$ titre.

Plaque reduction neutralisation test. The PRNT used to specify the agent that elicited the response could not resolve $33.3 \%$ of the cross reactions between CHIKV and ONNV (antibody titres were within 2-fold), probably because both agents circulate in the study area. However, they clearly indicated that neutralising $\mathrm{Ab}$ titres against $\mathrm{ONNV}$ and $\mathrm{CHIKV}$ were generally very high, with $70 \%$ above 1:2560, indicating probable recent infections. In $48.1 \%$ of cases, neutralising Abs to ONNV had a titre at least 4-fold higher than those for CHIKV, indicating that the response was mounted to an infection with the ONNV, while in $14.8 \%$ of sera, Abs to CHIKV were at least 4-fold higher (Figure 2).

\section{DISCUSSION}

This research adds to the recent resumption of activities to monitor arbovirus circulation in Cameroon. The study of arboviruses in Cameroon was undertaken during the colonial era in the British part of the country then attached to the territory of Nigeria, and more extensively in the early years of independence of the country, mainly focusing around Yaoundé, the capital city. MacNamara reported the isolation the Kumba virus, which was ultimately recognised as a strain of the SFV (15), from Eretmapodites grahami mosquitoes. Joint teams from the Centre Pasteur du Cameroun and the ORSTOM continuously investigated the epidemiology, ecology and dynamics of arboviral transmission from 1963 to the mid-1970s, including identification of vectors and potential reservoirs (16-19). Their investigations yielded among other major achievements the

Figure 2

Comparative chart of neutralising antibodies for CHIKV and ONNV

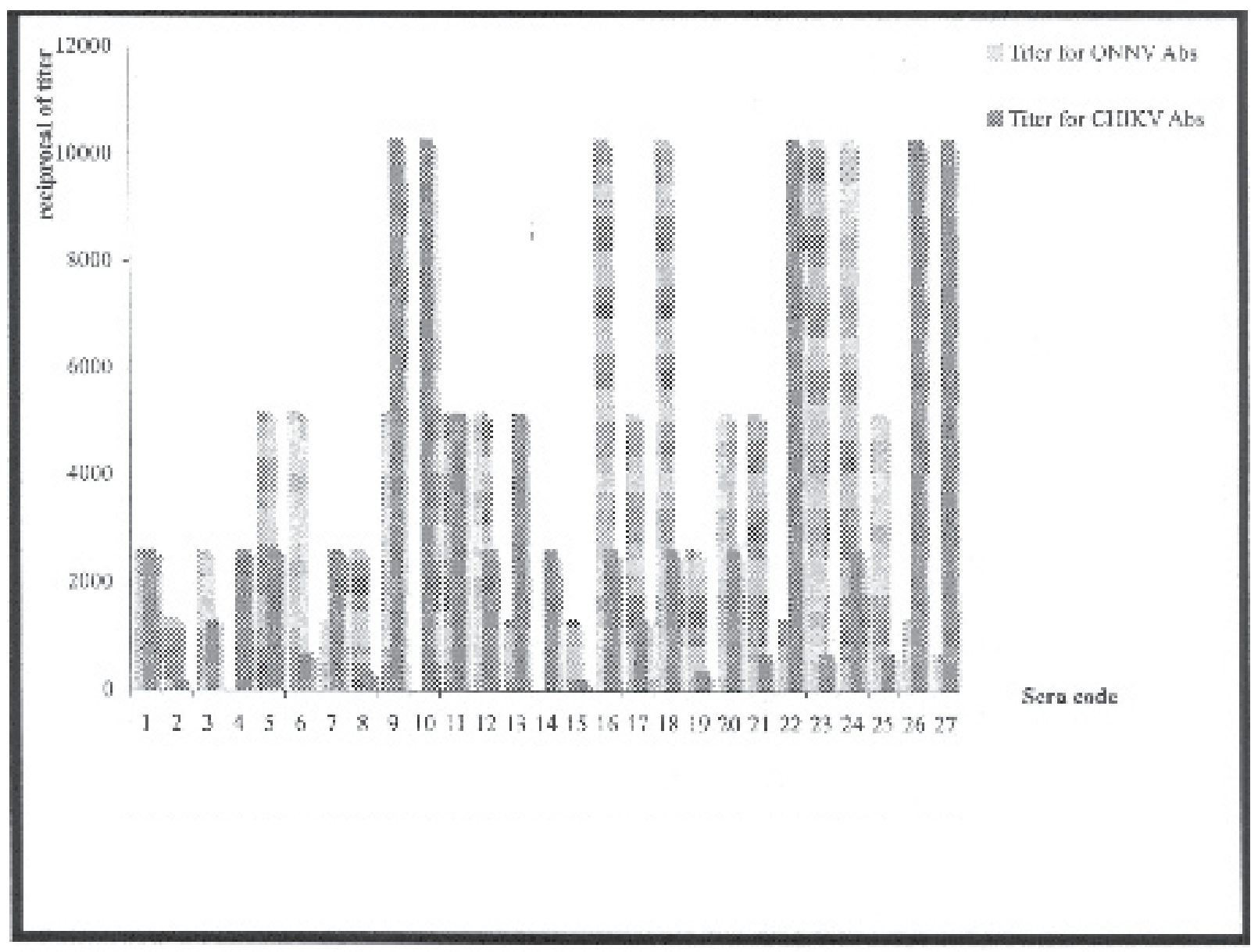


discovery of three new viruses, Nkolbisson virus of the Rhabdoviridae, Okola virus of the family Bunyaviridae, and Yaoundé virus of the genus Flavivirus, as well as indicated that at least 23 arboviruses circulated in the forests of Cameroon (20). However, they found no evidence for the presence of any of the major human arboviruses known from other parts of Africa (16,19-24).

Our findings indicate that several arboviral infections of humans are probably endemic in Cameroon and that two or more arboviruses probably infect many people. This is especially true for infections with ZIKAV, ONNV and CHIKV, for which there is a relatively high prevalence of $A b s$ and very high neutralisation titers (Figure 2). Although these agents have never been, or are rarely isolated in Cameroon, the prevalence of the ONNV antibodies appears to be higher than that of the CHIK as had been observed in natural reservoirs (17). This may be accounted for by the fact that ONNV is transmitted by the malaria vectors (Anopheles spp.), which are certainly the most abundant African haematophagous insects. Posey and his collaborators (25) recently recorded an outbreak of ONNV in a refugee camp in Coted'Ivoire and recommended laboratory diagnosis for arboviruses when massive outbreak of febrile rash illness occurs. CHIKV and ONNV are two closely related alphaviruses that are difficult to distinguish clinically or using serology, and for many years ONNV was considered by some investigators as a variant of CHIKV. Chikungunya, although not usually fatal, is a very painful and seriously debilitating disease. It recently caused an important epidemic on islands in the Indian Ocean (La Reunion, Comoros and Madagascar) with more than 300,000 cases reported, a major epidemic in India with up to 6.5 million cases, and also caused a small epidemic in Italy. Reports of fatalities and transmission from mother to child accompanied these epidemics (4). ZIKAV, which had not been previously reported in Cameroon, appears as the most important Flavivirus of humans in the Fako Division accounting for more than $11 \%$ of the fevers of unknown origin. It was found infecting patients in neighbouring Nigeria and causing an epidemic with symptoms including jaundice (26). Three of the patients having Abs to ZIKA in our study displayed jaundice, which was also seen in two patients with DENV-2 abs and one patient with YFV and WSLV. Yellow fever had not been reported from Cameroon since the last epidemics that affected the Adamawa highlands of the country and was poorly documented. The abs to YFV found in our study surely resulted from exposure to infectious mosquito bites because none of the positive patients had been vaccinated for YF. The data gathered in this survey enabled us determine that there was a high risk for an outbreak of YF in Fako, which was confirmed last September 2009 with two confirmed cases of infection. There is now a national vaccination scheme for $\mathrm{YF}$ in the country and data suggest that between $72-87 \%$ of the population is now covered (27). The serotypes of DENV (-1 and -2) known to occur in Africa are also present in Cameroon. DENV-2 is on of the fastest spreading infectious agents in the world. Its importance in Cameroon is probably overlooked just like that of the other arboviruses because the area is endemic for malaria and typhoid fever for which diagnosis is readily available. Our findings generally corroborate those of recent studies in Cameroon $(9,10)$. However, we have surprisingly not diagnosed any evidence of exposure to TAHV, which is relatively high in the study of Kuniholm and collaborators (10). This suggests more in-depth investigation to map the relative distribution of the various Arboviruses that circulate in the area.

\section{ACKNOWLEDGEMENTS}

This paper is dedicated to the memory of Dr. Veronica N.L. Dickmu who was instrumental in the collection of sera. EBF was supported by NIH/Fogarty grant No TW006590 to Dr David H. Walker of the UTMB. This research was also supported by NIH grants AI25489 and AI069145.

\section{REFERENCES}

1. Karabatsos, N. InternationalCatalogue of Arboviruses Including Certain Other Viruses of Vertebrates. Third Edition, San Antonio, Texas: Amer. Soc. Trop. Med. Hyg. 1985.

2. Gubler, D.J., Dengue, and Dengue Hemorrhagic Fever. In: Guerrant R.L., Walker D.H. and Weller P.F. (eds). Tropical infectious diseases, $2^{\text {nd }}$ edition, ChurchillLivingstone. 2006; 813-822.

3. Beaty, B.J., Calisher, C.H. and Shope, R.E. Arboviruses. In: Lennette E.H., Lennette D.E. and Lennette E.T. (eds). Diagnostic procedures for viral, rickettsial and chlamydial infections, $7^{\text {th }}$ edition. Washington, DC: Amer. Pub. Hlth. Assoc. 1995; 189-212.

4. Calisher, C.H.Persistentemergence of dengue. Emerg Infect Dis [serial on the Internet]. Available from http: / / www.cdc.gov/ ncidod/EID/vol11no05/050195.htm. 2005.

5. Enserink, M. Infectious diseases: massive outbreak draws fresh attention to little-known virus. Science. 2006; 311: 1085.

6. Sureau, P., Ravisse, P., Germain, M., et al. Isolement du virus Thogoto à partir de tiques Amblyomma et Boophilus en Afrique Centrale. Bull. Soc. Pathol. Exot. Filiales 1976; 69: 207-212.

7. Rickenbach, A., Le Gonidec, G. and Ravisse, P. L'incidence des arbovirus isolés des moustiques dans une région forestière du sud Cameroun, la région de Yaoundé. Bull. Soc. Pathol. Exot. Filiales. 1976; 69: 372-381.

8. Fontenille, D. and Toto, J.C. Aedes (Stegomyia) albopictus (Skuse), a potential new dengue vector in Southern Cameroon. Emerg. Infect. Dis. 2001; 7: 1066-1067. 
9. Ndip, L.M., Bouyer, D.H., Travassos Da Rosa A.P.A., et al. Acute spotted fever rickettsiosis among febrile patients, Cameroon. Emerg. Infect. Dis. 2004; 10: 432437.

10. Kuniholm, M.H., Wolfe, N.D., Huang, C.Y-F., et al. Seroprevalence and distribution of Flaviviridae, Togaviridae and Bunyaviridae arboviral infections in rural Cameroonian adults. Am. J. Trop. Med. Hyg. 2006; 74: 1078-1083.

11. Demanou, M., Antonio-Nkondjio, C., Ngapana E., et al. Chikungunya outbreak in a rural area of Western Cameroon in 2006: a retrospective serological and entomological survey. BMC Res. Notes, 2010; 3: 128.

12. Peyrefitte, C.N., Rousset, D., Pastorino, B.A.M., et al. Chikungunya virus, Cameroon, 2006. Emerg. Infect. Dis. 2007; 13: epub.

13. Fulton, F. and Dumbell, K.R. The serological comparison of influenza virus. J. Gen. Microbiol. 1946; 3: 97-111.

14. Tsai, T.F. and Chandler, L.J. Arboviruses. In: Murray P.R. (ed.) Manual of Clinical Microbiology, $8^{\text {th }}$ edition, Washington DC, ASM Press, 2003: 1553-1569.

15. MacNamara F.N. The susceptibility of chicks to Semliki Forest virus (Kumba strain). Ann. Trop. Med. Parasitol. 1953; 47: 9-12.

16. Brottes, H., Rickenbach, A., Bres, P., et al. Le virus Okola (YM50-64), Nouveau prototype d'arbovirus isolé au Cameron à partir de moustiques. Ann. Inst. Pasteur 1969; 116: 54-51.

17. Poirier, A., Germain, A., Rickenbach, A. and Eouzan, J-P. Recherche sur le réservoir animal d'arbovirus dans une région forestière du Cameroun, communication préliminare. Bull. Soc. Pathol. Exot. Filiales. 1969; 62: 63-72.

18. Salaun, J.J., Rickenbach, A., Bres, P., et al. Isolement au Cameroun de trois souches de virus Tataguine. Bull. Soc. Pathol. Exot. Filiales 1968; 61: 557-564.
19. Salaun, J.J., Rickenbach, A., Bres, P., et al. Le virus Nkolbisson (YM31-65), nouveau prototype d'arbovirus isolé au Cameroun. Ann. Inst. Pasteur. 1969; 116: 254260.

20. Anonymous. 2000. Rapport annuel $2000 \mathrm{du}$ Centre CollaborateurOMS de Referenceet de Recherche pour les Arbovirus et Virus de Fievres Hemorragiques. OMS, Dakar, 139p.

21. Salaun,J.J., Rickenbach, A., Bres P., et al. Les arbovirus isolés à partir de moustiques au Cameroun. Bull. World Hlth. Org. 1969; 41: 233-241.

22. Brottes, H., Rickenbach, A., Bres, P., Salaun, J.J. and Ferrara, L. Les arbovirus au Cameroun; isolements à partir de moustiques. Bull. World Hlth. Org. 1966; 35: 811-825.

23. Rickenbach, A., Germain, M., Eouzan, J-P. and Poirier, A. Recherches surl'épidémiologie des arbovirus dans une région forestière du Sud Cameroun. Bull. Soc. Pathol. Exot. Filiales. 1966; 62: 266-276.

24. Zeller, H.G., Karabatsos, N., Calisher, C.H., et al. Electron microscopic and antigenic studies of uncharacterized viruses. II. Evidence suggesting the placement of viruses in the family Bunyaviridae. Arch. Virol. 1989; 108: 211-227.

25. Posey, D.L., O'rourke, T., Roehrig, J.T., et al. O'nyongNyong fever in West Africa. Am. J. Trop. Med. Hyg. 2005; 73: 32.

26. MacNamara, F.N. Zika virus: a report on three cases of human infection during an epidemic of jaundice in Nigeria. Trans. Roy. Soc. Trop. Med. Hyg. 1954; 48: 139-145.

26. Wiysonge, C.S., Nomo, E., Mawo, J., et al. Yellow fever control in Cameroon: where are we now and where are we going? BMC Med. 2008; 6: 3. 